\title{
Compartment Pressure Monitoring After Thyroid Surgery: A Possible Method to Detect a Rebleeding
}

\author{
Sabaretnam Mayilvaganan ${ }^{1} \cdot$ Sapana Bothra $^{1}$
}

Published online: 8 August 2017

(C) Société Internationale de Chirurgie 2017

\section{Dear Sir,}

We read with interest the article "Compartment Pressure Monitoring after Thyroid Surgery: A Possible Method to Detect a Rebleeding" by Thomas van Ahnen et al. [1]. We congratulate the authors on their effort to address an important issue of post-thyroidectomy bleed or haemorrhage which can be at times life threatening. This study addresses the need to continuously monitor pressures as an attempt to identify the herald bleed which may be disastrous if left untreated. We most of the times encounter postthyroidectomy bleed from either the artery or the vein, commonly from the strap muscle [2], and sometimes the bleeder is not found at all.

We have few queries which may benefit future readers. What did the authors use for haemostasis the traditional tie and cut method, ultrasonic or Ligasure devices? Did authors use haemostatic agent like oxidized cellulose polymer (Surgicel)? The patient who bled and underwent re-exploration, was he hyperthyroid? What did the final histopathology reveal? Have the authors tried this technique in thyroid cancer patients as well?

Thank you for your comments on these issues.

Sabaretnam Mayilvaganan

Sapana Bothra

\section{References}

1. von Ahnen T, von Ahnen M, Militz S, Preußer D, Wirth U, Schardey HM, Schopf S (2017) Compartment pressure monitoring after thyroid surgery: a possible method to detect a rebleeding. World J Surg. doi:10.1007/s00268-017-4020-9

2. Perera M, Anabell L, Page D, Harding T, Gnaneswaran N, Chan S (2016) Risk factors for post-thyroidectomy haematoma. J Laryngol Otol 130(Suppl 1):S20-S25. doi:10.1017/S0022215115003199
Sabaretnam Mayilvaganan

drretnam@gmail.com

1 Department of Endocrine and Breast Surgery, Sanjay Gandhi Postgraduate Institute of Medical Sciences, Lucknow, India 